R. C. Hawes, J. biol. Chemistry 133, 375 (1944). - 11. Breuer, H. und M. Schönfelder, Clin. chim. Acta, Amsterdam 6, 515 (1961). 12. Pilz, W., diese Z. 5, 1 (1967). - 13. Pilz, W. und I. JohanN, diese Z. 4, 215 (1966). - 14. Augustinsson, K.-B., Meth. biochem. Analysis 5, 1 (1957). - 15. HardegG, W., in Hoppe-Seyler/Thierfelder: Handbuch der physiologisch- und pathologisch-chemischen Analyse, Bd. VI/B, S. 921, 10. Aufl., Springer Berlin (1966). - 16.
Report of the Commission on Enzymes of the International Union of Biochemistry, Pergamon Press, Oxford, London; New York, Paris 1961. - 17. Przz, W., Hoppe-Seyler's Z. physiol. Chem. 345, 80 (1966). - 18. Härtel, A., W. Gross und H. LANG, diese Z. 5, 26 (1967). - 19. Schmidinger, St. und A. Doenicke, diese Z. 4, 273 (1966). - 20. Thompson, J. C. und M. WhitTAKeR, J. Clin. Path. London 18, 811 (1965).
Dr. H. Willgerodt $X 705$ Leipzig Oststraßc. $21-25$

\title{
Erfahrungen mit einer kolorimetrischen Methode zur Bestimmung der nicht veresterten Fettsäuren im Serum ${ }^{1}$ )
}

\author{
Von P. Dieterle, C. Wülfert-Heldrich, J. Henner und K. Schwarz \\ Aus der II. Medizinischen Klinik der Universität München (Direktor: Prof. Dr. Dr. G. Bodecbtel)
}

(Eingegangen am 26. Januar 1968)

Es wird über eigene Erfahrungen mit der kolorimetrischen Bestimmung der NFS nach DuNcombE $(6,7)$ berichtet. Es besteht eine gute Korrelation beim Vergleich des beschriebenen Verfahrens mit der Titrationsmethode nach DoLE $(1,2)$. Die Vorteile der Methode werden besprochen.

Studies are reported on the colorimetric determination of nonesterified fatty acids according to DuncomBE $(6,7)$. There is good correlation between the described method and the titration method of Dole $(1,2)$. The advantages of the methods are discussed.

Eine in der klinischen Medizin gebräuchliche Bestimmungsmethode ist die Messung der nicht veresterten Fettsäuren $(\mathrm{NFS})^{2}$ ) im Serum mit dem Titrationsverfahren nach DoLE bzw. Dole und MEINERTz $(1,2)$. Trotz guter Reproduzierbarkeit ist diese Methode nicht ganz frei von Nachteilen. Ein anderes Verfahren zur Bestimmung der NFS mittels Kolorimetrie hat 1956 Ayers (3) mitgeteilt, das 1959 von Iwayama (4) und 1961 von BARRETO und MaNo (5) weiter modifiziert wurde. Von Duncombe $(6,7)$ wurde schließlich die Methode in ihrer Empfindlichkeit so verbessert, $\mathrm{da} ß$ sie sich gut für klinische und biochemische Fragestellungen eignet. Unsere Erfahrungen mit dieser kolorimetrischen Methode und die Vorteile gegenüber dem Titrationsverfahren sollen in dieser Arbeit anhand vergleichender Untersuchungsreihen herausge-stellt und beurteilt werden.

\section{Methodik}

Prinzip

Die NFS werden als Kupfersalze mit Chloroform extrahiert. Die Kupferseifen werden mit Diäthyldithiocarbaminat in einen Kupferkomplex überführt und kolorimetrisch bestimmt.

\section{Reagenzien}

1. Chloroform p. a.

2. Kupferreagenz:

a) $\mathrm{Cu}\left(\mathrm{NO}_{3}\right)_{2} \cdot 3 \mathrm{H}_{2} \mathrm{O}, 6,45$ proz. Lösung,

b) 9 Teile $1 \mathrm{M}$ Triäthanolamin +1 Teil 1N Essigsäure a) und b) werden im Verhältnis 1:1 gemischt.

3. Natrium-Diäthyldithiocarbaminat $\left(\mathrm{C}_{5} \mathrm{H}_{10} \mathrm{~N} \mathrm{NaS} \cdot 3 \mathrm{H}_{2} \mathrm{O}\right)$. Es wird eine 0,1proz. Lösung in sek. Butanol hergestellt.

Lösung 2 und 3 müssen im Kühlschrank aufbewahrt und jede Woche erneuert werden.

1) Mit Unterstützung der Deutschen Forschungsgemeinschaft.

2) Abktirzungen: NFS = nicht veresterte Fettsäuren.

\section{Durchfiibrung}

In ein geschliffenes Reagenzglas werden $5 \mathrm{~m} /$ Chloroform (bzw. in $5 \mathrm{ml}$ gelöster Palmitinsäurestandard), $2,5 \mathrm{~m} /$ Kupferreagenz und $0,5 \mathrm{ml}$ Serum pipettiert. Nach sorgfältigem Verschluß der Schliffgläser (wir verwenden dafür lipoidunlösliche Kunststoffstopfen) wird das Gemisch in einer dreidimensionalen Schüttelapparatur $30 \mathrm{Min}$. gleichmäßig geschüttelt. Anschließend wird das Gemisch $15 \mathrm{Min}$. bei 2000 bis $3000 \mathrm{~g}$ zentrifugiert. Es bilden sich 2 Phasen. Die obere wäßr. Phase mit dem überschüssigen Kupferreagenz ist von der unteren Chloroformphase durch eine ausgefällte Eiweißschicht getrennt. Mit einer an die Wasserstrahlpumpe angeschlossenen Kapillare wird nun einschließlich der an der Glaswandung haftenden Tropfen die obere Kupferphase und anschließend vorsichtig die Eiweißschicht abgesaugt. Vom Chloroformrückstand werden sofort $3 \mathrm{~m} /$ in ein kleines Schliffglas abpipettiert. Dabei ist sorgfältig darauf zu achten, daß die Pipette nicht die Glaswandung berührt und damit Kupfer überträgt. Zur Chloroformphase werden $0,5 \mathrm{~m} /$ 'der Diäthyldithiocarbaminatlösung gegeben und der gelbgefärbte Kupferkomplex bei $436 \mathrm{~nm}$ (Photometer Eppendorf) gegen einen Reagenzienblindwert, der durch die gesamte Messung mitläuft, innerhalb einer Stunde gemessen.

Die Berechnung erfolgt nach der Formel

Extinktion Probe $\cdot \frac{\mu \mathrm{Val} / / \text { des Standards }}{\text { Extinktion Standard }} \cdot 10=\mu \mathrm{Val}$ NFS $/ /$ Serum

Diskussion der Methode

Bestimmungen von reinen Palmitinsäurelösungen zeigen, daß zwischen der Konzentration und der Extinktion strenge Proportionalität besteht (Abb. 1). Es genügt daher im allgemeinen, nur einen Palmitinsäurestandard mitlaufen zu lassen. In weiteren Versuchen wurde Natriumpalmitat an Serumalbumin gebunden und anschließend die Wiederfinderate bestimmt. Im Mittel wurden $98 \%$ des eingesetzten Palmitat-Standards wiedergefunden. Dies stimmt mit Angaben von ITAYA und UI (8) überein. Die geringere Wiederfindequote von Duncombe (7) führen wir auf 


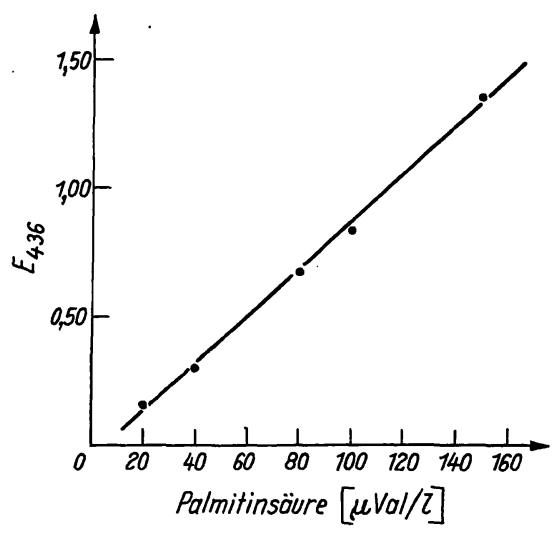

Abb. 1

Standard-Eichkurve: Die in der Eichkurve eingesetzten Palmitinsäurestandards von 20 bis $150 \mu \mathrm{Val} / \mathrm{l}$ entsprechen auf Serum bezogen einem Bereich von 200 bis $1500 \mu \mathrm{Val} / l$, da die Standardlösungen im 10fachen Volumen bestimmt werden

die kürzere Schüttelzeit zurück, da die Freisetzung der NFS aus der lockeren Albuminbindung weitgehend von der Extraktionsdauer abhängig ist (siehe auch Abb. 2). Der Variationskoeffizient $\frac{s}{\bar{x}} \cdot 100$ liegt bei 3,5\% (Mittelwert aus 9 Fehlerbestimmungen ( $\mathrm{n}=8$ bis 11) mit jeweils gleichen Sera), läßt sich aber bei einiger Übung bis auf $2 \%$ verringern. Der Variationskoeffizient von 3,5\% entspricht bei einem tatsächlichen Wert von $400 \mu \mathrm{Val}$ NFS/l einem Absolutwert von $\pm 14 \mu \mathrm{Val} / \mathrm{l}$.

In jüngster Zeit sind eine Reihe weiterer Verfahren zur kolorimetrischen Bestimmung der NFS angegeben worden (8-12). Diese Modifikationen unterscheiden sich von der beschriebenen Methode darin, daß entweder andere Extraktionslösungen verwandt werden oder daß die Seifen- und Komplexbildung mit anderen Metallen (Kobalt, Uran) erfolgt. Der Variationskoeffizient ist bei all diesen Verfahren ähnlich und liegt nicht niedriger als bei der Methode nach Duncombe $(6,7)$. Von Bedeutung erscheint uns allerdings, daß ITAYA und Ur (8) die NFS auch im Vollblut bestimmen, da sie durch Zugabe eines Phosphatpuffers den Übertritt von Hämoglobin in die Chloroformphase verhindern. Hämolytisches Serum geht aber störend in die Messung beim Verfahren nach Duncombe $(6,7)$ ein.

\section{Fehlerquellen}

1. Sofortiges Überschichten des Chloroforms mit der wäßr. Kupferphase zu Beginn des Arbeitsganges verhindert ein Verdampfen von Chloroform.

2. Von großer Bedeutung ist eine streng genormte Schüttelzeit. Die Extraktion der NFS aus dem komplexen Gemisch des Serums ist zeitabhängig. Untersuchungen zeigen, daß die Extraktion nach $10 \mathrm{Min}$. noch tiicht abgeschlossen ist und eine nicht unbeträchtliche Mehrausbeute aus dem gleichen Serum nach Verlängerung der Schüttelzeit auf 30 Min. zu erwarten ist (Abb. 2). Nach 30 Min. scheint die Extraktion dagegen nahezu vollständig. Die geringe Mehrausbeute nach $40 \mathrm{Min}$. Schüttelzeit liegt innerhalb der Fehler-

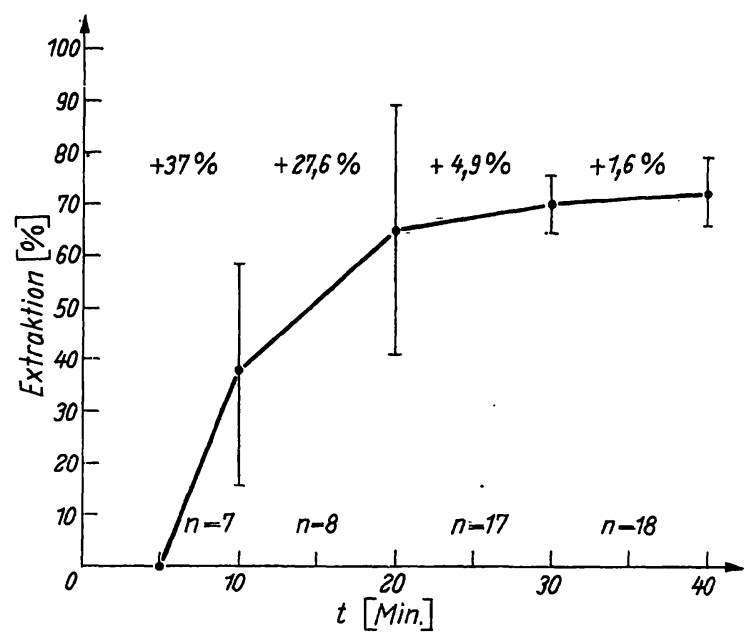

Abb. 2

Einfluß der Schüttelzeit auf die Extraktion der nicht veresterten Fettsäuren aus dem Serum. Die prozentuale Mehrausbeute bei Verlängerung der Schüttelzeit ist als Mittelwert $\pm s$ angegeben. Bis zu $30 \mathrm{Min}$. ist mit einer zunehmenden Extraktion an nicht veresterten Fettsäuren aus dem Serum zu rechnen. Nach der 30 . Min. liegen die Extraktionsänderungen innerhalb der Fehlbreite der Methode

breite der Methode. Die von Duncombe $(6,7)$ und auch in einer Testpackung der Firma Haury angegebene Schüttelzeit von 2 Min. erscheint uns in jedem Fall zu gering, da die Extraktion der NFS aus dem Serum zu diesem Zeitpunkt sicher nicht quantitativ erfolgte und bereits geringe Änderungen in der Schüttelzeit nicht reproduzierbare Ergebnisse bringen können.

3. Nicht zu empfehlen ist das Schütteln von Hand, da dabei häufig ein schlecht zentrifugierbarer Eiweißschaum entsteht. Das Abpipettieren des Chloroformrückstandes nach Absaugen der Kupferphase und der Eiweißschicht muß mit.großer Sorgfalt durchgeführt werden. Berührt man die Glaswandung, können bereits Spuren von Kupfer das Ergebnis erheblich verfälschen. Für Ungeübte besteht die Möglichkeit, nach halbquantitativem Absaugen der Kupfer- und Eiweißschicht letzte Spuren von überschüssigem Kupfer durch Filtration des Zentrifugates $z u$ entfernen. Wir selbst haben darüber keine Erfahrungen, da uns der Fehler durch Verdampfen des Chloroforms auf der Oberfläche des Filters zu groß erschien. Nach IтAYA und UI (8) ergeben sich durch Filtration aber keine zusätzlicher Fehler.

4. Nach Zugabe der Farblösung zur Chloroformphase müssen die Gläschen bis zur Messung, die innerhalb einer Stunde erfolgen sollte, erneut verschlossen werden, um ein Abdampfen von Chloroform zu vermeiden. Schließlich sind als weitere Störfaktoren hämolytisches und ikterisches Serum zu erwähnen. Durch Zugabe eines Phosphatpuffers (8) kann aber der Übertritt von Hämoglobin in die Extraktionslösung vermieden werden. In der Modifikation von Novak (12) geht Bilirubin nicht in die Messung ein, jedoch werden von diesem Autor die beim Ikterus vermehrt auftretenden Gallensäuren nicht berücksichtigt.

Vermeidet man die beschriebenen Fehlerquellen, zeichnet sich die Methode durch gute Reproduzierbarkeit aus. 


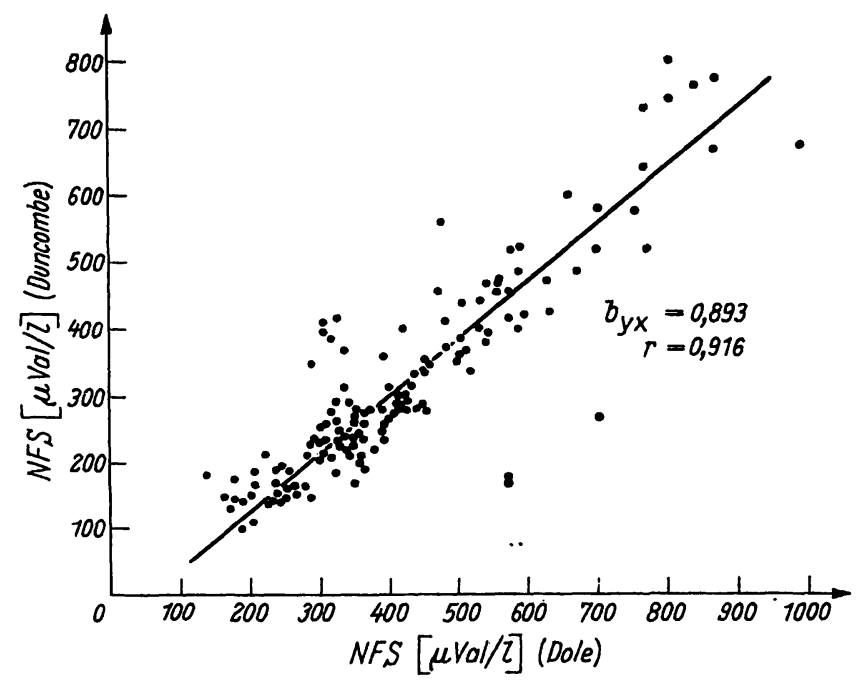

Abb. 3

Vergleich der Methoden zur Bestimmung der nicht veresterten Fettsäuren (NFS) nach Dole und Duncombe.

138 Seren wurden jeweils am gleichen Tag nach verschiedenen Methoden bestimmt. Es besteht eine gute Korrelation. Mit der kolorimetrischen Methode wurden etwas geringere Werte als mit der

Ein Vergleich der beschriebenen Methode mit dem Titrationsverfahren nach DoLE $(1,2)$ zeigt eine gute Korrelation (Abb. 3). Die Bestimmung von 138 Seren nach den beiden Methoden wurde jeweils am gleichen Tag als Doppelbestimmung vorgenommen. Mit dem kolorimetrischen Verfahren nach Duncombe $(6,7)$ erhielten wir durchschnittlich etwas niedrigere Werte an NFS. Dies stimmt mit Angaben aus der Literatur überein $(7,10,13,14)$. Diese Unterschiede sind zum Teil darauf zurückzuführen, daß bei dem Verfahren nach Dole $(1,2)$ teilweise auch die kurzkettigen aliphatischen Säuren durch Titration erfaßt werden. Nach Duncombe $(6,7)$, Anstall und Trujillo (13) und Kvam und Mitarbeiter (10) werden aber die weniger als $8 \mathrm{C}$-Atome enthaltenden Säuren durch
Chloroform nicht extrahiert und gehen deshalb nicht in die kolorimetrische Bestimmung ein. Bei beiden Methoden werden die Phospholipide teilweise miterfaßt. Durch besondere Verfahren $(8,9,11,13)$ können sie quantitativ entfernt werden. Für klinische Fragestellungen dürfte es von Interesse sein, daß Tolbutamid im Gegensatz zur Methode nach Dole $(1,2)$ nicht in die kolorimetrische Bestimmung nach Duncombe $(6,7)$ eingeht.

Vorteile der kolorimetrischen Bestimmung der NFS gegenüber der Titrationsmethode nach DOLe $(1,2)$

1. Die eingesetzten Serummengen sind geringer. (Es kann auch mit weniger als $0,5 \mathrm{~m} l$ Serum gearbeitet werden. Es empfiehlt sich jedoch zu Vergleichszwecken, stets gleiche Volumina zu verwenden, da bei geringeren Serummengen die Extraktion der NFS geringgradig zunimmt. Bei der Mikromethode von Novak (12) werden $50 \mu l$ Serum eingesetzt.)

2. Der subjektive Fehler beim Ablesen des Indikatorumschlages bei der Titrationsmethode fällt durch Extinktionsmessung weg.

3. Während bei der Titrationsmethode teilweise auch die kurzkettigen aliphatischen Säuren erfaßt werden, gehen diese in die kolorimetrische Bestimmung nicht ein.

4. Der Variationskoeffizient liegt niedriger.

5. Tolbutamid geht nicht in die Bestimmung ein, was für die Untersuchung von mit oralen Antidiabetica behandelten Zuckerkranken von Bedeutung ist.

6. Der Arbeitsaufwand ist geringer, die Arbeitskapazität demnach größer.

Herrn Dr. F. H. Schmidr von der Fa. Boehringer \& Söhne, Mannheim, sind wir für seine Hilfe und seizen Rat zu großem Dank verpflichtet.

\section{Literatur}

1. Dole, V. P., J. Clin. Invest. 35, 150 (1956). - 2. Dole, V. P. und H. Meinertz, J. biol. Chemistry 235, 2595 (1960). - 3. Ayers, C. W., Analytica chim. Acta Amsterdam 15, 77 (1956). - 4. IwAYAMA, Y., J. pharm. Soc. Japan. 79, 552 (1959). - 5. BARreto, R. C. R. und D. B. Mano, Clin. chim. Acta (Amsterdam) 6, 889 (1961). - 6. Duncombe, W. G., Biochem. J. 88, 7 (1963). 7. Duncombe, W. G., Clin. chim. Acta (Amsterdam) 9, 122 (1964). - 8. ItrayA, K. und M. Ur, J. Lipid. Res. 6, 16 (1965). -
9. Antonis, A., J. Lipid. Res. 6, 307 (1965). - 10. Kvam, D. C., J. G. Schmid, D. A. Riggrlo und D. G. Gallo, J. pharmaceut. Sci. 53, 988 (1964). - 11. MACKenzie, R. D., T. R. Blohis, E. M. Auxier und A. C. Luther, J. Lipid. Res. 8, 589 (1967). - 12. Novak, M., J. Lipid. Res. 6, 431 (1965). - 13. Anstall, H. A. und J. M. Trujillo, Clin. Chem. (New York) 11, 741 (1965). 14. Howorth, P. J. N., S. Grbbard und V. Marks, Clin. chim. Acta (Amsterdam) 14, 69 (1966).
Prof. Dr. K. Schwarz 8 München 15 Ziemssenstr. 1 